\title{
Cruzando diferenças nos Nordestes Brasileiros: novas agendas de pesquisa em gênero e sexualidade
}

É inegável a ampliação do campo dos estudos de gênero e sexualidade nos últimos anos. Esse crescimento vem sendo mapeado por alguns balanços da literatura que apontam tendências e mudanças relacionadas a essa produção (CITELI, 2005; AQUINO, 2006; FACCHINI, 2013). É consenso nesses balanços situar o final da década de 1970 e início da década de 1980 como um período de surgimento desses estudos associado a um avanço progressivo, no âmbito acadêmico, de trabalhos que visavam produzir um entendimento mais estreito de grupos urbanos considerados desviantes por suas condutas e comportamentos sociossexuais, tais como os homossexuais e as prostitutas (GASPAR, 1985; FRY, 1982; FRY \& MACRAE, 1985), bem como em razão de suas práticas, classificações, formas de sociabilidade e estilos de vida (GUIMARÃES, 2005). Esses balanços também situam a eclosão da epidemia de HIV/aids como um momento de legitimação desse campo de estudos (AQUINO, 2006).

É possível afirmar ainda que esses trabalhos são o resultado de uma combinação entre produção de conhecimento e ativismo político agenciado pelo surgimento dos "novos movimentos sociais" no período de redemocratização da sociedade brasileira. Ainda na década de 1960, o movimento feminista passaria a produzir uma ampla quantidade de estudos sobre temas como a participação da mulher na força de trabalho, a divisão sexual do trabalho, a família patriarcal etc (LOYOLA, 2000). Uma característica marcante desses trabalhos é sua vinculação com o marxismo e com uma ideologia igualitária que emerge entre as camadas médias urbanas. Essa percepção de igualdade estava associada às mudanças culturais e comportamentais que ocorriam, como a revolução sexual, o advento da pílula e as ideias libertárias propagadas pelo movimento hippie, tendo os Estados Unidos e a Europa como epicentros.

Nos estudos sobre as (homo)sexualidades, o trabalho de maior fôlego e repercussão nesse momento foi Da hierarquia à igualdade: a construção histórica da homossexualidade no Brasil, do professor Peter Fry. Nesse trabalho, Fry analisa as representações sobre a 
homossexualidade na cultura erótica de alguns contextos brasileiros. Ele sugere dois modelos classificatórios adotados no Brasil para organizar a homossexualidade, o "hierárquico" e o "igualitário". A construção desse modelo interpretativo possibilitou a desessencialização da homossexualidade, ressaltando, sobretudo, o seu caráter histórico e cultural. Esse trabalho marca, ainda, uma "passagem" definitiva, na qual a homossexualidade é retirada do campo dos saberes médicos e consequentemente incorporada ao campo da Antropologia.

Igualmente importantes foram as questões trazidas por um intelectual argentino (mestrando da UNICAMP na época) que antecipariam debates hoje considerados centrais nas Ciências Humanas. A preocupação com os chamados michês ou garotos de programa da região central da cidade de São Paulo foi, sem sombra de dúvida, fundamental para propor reflexões pioneiras sobre corpo, sexualidade, territorialidades e construção de modelos de masculinidades operacionalizadas pelo autor argentino em sua análise (PERLONGHER, 1987).

Essas contribuições influenciaram toda uma geração de estudiosas e estudiosos responsáveis pelo amadurecimento desse campo de estudos no país. Nos últimos anos temos assistido a um crescimento expressivo das produções científicas que se dedicam a analisar a maneira como o cruzamento de distintos eixos de diferenciação e desigualdades produzem e materializam formas de classificação de sujeitos, desejos, erotismos, desvantagens, violências e agenciamentos. Muitas dessas pesquisas têm se concentrado no eixo Rio-São Paulo, onde, também, se destacam a presença de núcleos, pesquisadoras/es e linhas de pesquisa relacionadas à consolidação dessa forma de abordagem.

Com a expansão do ensino superior no Brasil, regiões brasileiras geograficamente distantes desses grandes centros urbanos passaram a receber instituições de ensino que têm produzido um volume significativo de pesquisas nos locais em que estão sediadas ${ }^{1}$. A abertura de novas vagas para docentes nessas instituições também colaborou para a diversificação temática e a construção de novas agendas de pesquisas relacionadas a gênero e sexualidade nessas instituições. Como reflexo dessa dinâmica é possível observar um conjunto crescente de

1 É importante destacar o protagonismo de pesquisadoras e pesquisadores inseridos em instituições como UFBA, UFS, UFPE, UFSC, UFRN, UFRB, UFG e UFRGS, que têm produzido um conjunto importante de trabalhos relacionados a gênero e sexualidade fora do eixo Rio-São Paulo. 
publicações reunidas em dossiês temáticos em revistas especializadas e de debates em Grupos de trabalho organizadas em eventos importantes do campo das Ciências Sociais como os Encontros Anuais da ANPOCS.

Em um primeiro dossiê temático intitulado "Diversidade Sexual e de Gênero em Áreas Rurais, Contextos Interioranos e/ou Situações Etnicamente Diferenciadas. Novos descentramentos em outras axialidades" publicado pela ACENO: Revista de Antropologia do Centro-Oeste (UFMT), em 2016, Estêvão Fernandes, Fabiano Gontijo, Martinho Tota e Moisés Lopes chamam a atenção para a fortuna teóricometodológica dos estudos rurais e de gênero e sexualidade na antropologia brasileira. Os autores afirmam, contudo, haver um desencontro entres esses dois campos de estudos, o que promove a invisibilidade das experiências e sentidos relacionados a gênero e sexualidade em contextos não urbanos.

Para estes autores, existe uma necessidade urgente de construir na tradição dos estudos de gênero e sexualidade, projetos de pesquisa que busquem analisar esse "pluriverso de afetos, sexualidades e desejos sem, necessariamente, adequá-lo ao conjunto de jargões, os quais, por conta das redes que constituem o campo dos estudos do gênero e sexualidade no país, tornaram-se gastos ou pouco adequados" (ESTÊVÃO et al, 2016, p. 12).

Ainda em 2016, um novo investimento desses autores resultou na publicação do dossiê "Experiências da Diversidade Sexual e de Gênero em Áreas Rurais, Contextos Interiorianos ou Periferizados e/ou Situações Etnicamente Diferenciadas: novos descentramentos em outras axialidades" pela Amazônica: revista de antropologia (UFPA). Nele, os autores propõem uma ampliação do olhar para questões as quais os estudos de gênero e sexualidade tradicionalmente não têm dedicado sua atenção.

Em 2019, Rafael Noleto, Claudia Turra Magni e Flávia Rieth coordenaram o dossiê "Cidades do interior, interior das cidades" na revista Ponto Urbe (USP) cujo foco era enredar o debate sobre os interiores no conjunto das pesquisas da "antropologia na/da cidade" fazendo emergir nos oito artigos que compunham o dossiê esse "urbano interior".

Os silêncios em torno dos estudos de gênero e sexualidade em contextos interioranos e/ou rurais foram novamente retomados como argumento no dossiê "Dissidências de gênero e sexualidade(s) em 
contextos interioranos e/ou rurais: cruzando temas, problemas e perspectivas contemporâneas" publicado pela Revista Debates Insubmissos, em 2020. Nesse dossiê, as/os autoras/es propõem um deslocamento do olhar para incluir, inclusive, produções em contextos da América Latina.

No $43^{\circ}$ Encontro Anual da Associação Nacional de Pósgraduação e Pesquisa em Ciências Sociais - ANPOCS (2019), as professoras Elisete Schwade e Silvana de Souza Nascimento, coordenaram o Simpósio Temático "Ciências Sociais pelos interiores: novas cartografias de pesquisa em gênero e diversidade sexual no Brasil". Nele, foram apresentados treze trabalhos vinculados a pesquisadoras e pesquisadores de diferentes instituições que desenvolvem suas investigações nos interiores do País. No $44^{\circ}$ Encontro anual da Associação Nacional de Pós-graduação e Pesquisa em Ciências Sociais - ANPOCS (2020), o foco nos interiores brasileiros ganhou destaque nos quatorze trabalhos reunidos no "GT Gênero e Sexualidade pelo interior do Brasil: fronteiras e cartografias" coordenado pelas mesmas pesquisadoras. Essas iniciativas revelam a pluralidade dos temas que compõem as investigações apresentadas, a diversidade regional e a contribuição que estas pesquisas trazem à produção de conhecimento das Ciências Sociais brasileiras.

Dialogando com essa nova geografia da produção intelectual articulada às agendas de pesquisa com foco nas teorias interseccionais e decoloniais, este dossiê propôs reunir trabalhos de pesquisadoras e pesquisadores que tomaram os Nordestes brasileiros como espaços privilegiados de construção de suas pesquisas. Buscou-se, assim, refletir como esses territórios estruturam formas específicas de produção das diferenças, desigualdades, resistências e formas de agenciamento, e contribuem para dar visibilidade aos problemas de ordem social investigados. $\mathrm{O}$ foco desse dossiê também recaiu sobre as dificuldades e potencialidades encontradas por investigadoras e investigadores para realização de suas pesquisas nesses diversos Nordestes.

Os doze artigos aqui reunidos abrangem temas como performances de gênero, formas de violência, trajetórias, pedagogias, sociabilidades, consumo e sexualidades dissidentes que expressam formas específicas de olhar os Nordestes. As diferentes performances e expressões de gênero são focalizadas em três artigos desse dossiê. O trabalho Narrativas aguendadas: (micro)políticas de negociação estabelecidas por uma estudante trans* no Ensino Superior de 
Alfrancio Ferreira Dias e Madson de Santana Santos partem da trajetória de uma estudante trans* do curso superior de Letras Vernáculas da Universidade Federal de Sergipe (Campus do interior) para compreender as possibilidades de (re)existência e (re)negociações das aprendizagens de gênero nessa universidade a partir do processo de aquendar-se e desanquendar-se.

No artigo $O$ (des)acesso de pessoas transgêneras aos serviços de saúde do Recôncavo Baiano de Helena Moraes Cortes, Paula Hayasi Pinho, Ligia Maffei Carnevalli e Lorena Moura Pontes Araújo analisam o acesso de pessoas transgêneras aos serviços de saúde em uma cidade do Recôncavo da Bahia. Em Performances de gênero no Maracatu Rural pernambucano: travestilidade masculina em um folguedo popular, Anderson Vicente da Silva problematiza a relação entre cultura popular, gênero e sexualidade a partir das performances do Maracatu Rural que ocorre em Nazaré da Mata, Pernambuco.

A relação entre consumo, sociabilidade e territórios aparece em dois trabalhos do dossiê. No artigo Os usos de aplicativos de relacionamento: intersecções entre gênero, sexualidade e raça no Recôncavo Baiano, Marco Antonio Vieira de Oliveira Paranhos e Maria Salete de Souza Nery focalizam o consumo de aplicativos de relacionamento entre homens com "condutas homossexuais" em cidades do Recôncavo da Bahia.

Os paredões de som em Canaan, interior do Ceará, é o cenário etnográfico do artigo "Esquemas" de pista de terra batida: paredões de som, consumo e sociabilidades em cidades de pequeno porte de autoria de Marcos Andrade Alves dos Santos e Roberto Marques. Nele, os autores analisam como corpos, erotismos e ritmos ressignificam compreensões sobre sentimentos de identificação e liberdade entre os jovens que frequentam esses paredões.

As intricadas relações entre gênero, sexualidade, violência e agência aparecem em quatro artigos do dossiê. No trabalho Sofrimento, família e homossexualidade: um estudo com estudantes universitários do Recôncavo da Bahia, Thiago Barcelos Soliva, Marcus Vinicius Silva Santiago Silva e Marcos Vinicius Nery Damasceno analisam a produção de narrativas sobre sofrimento, violências e silêncios relacionados à gestão da homossexualidade na trajetória de vida de jovens gays estudantes universitários em Santo Antônio de Jesus, Recôncavo da Bahia. 
A trajetória de sete mulheres usuárias de drogas na cidade de Teresina, Piauí, é focalizada no artigo Entre elas: ser e viver mulher usuária de substâncias psicoativas de Sara Alves Henriques e Lucia Rosa, os resultados revelam a complexidade das percepções sobre questões como família, sistema patriarcal e substâncias químicas.

Patrícia Rosalba Salvador Moura Costa, José Maria Valcuende Del Río, Elielma Santos Macedo, Leila Oliveira Silva analisam no artigo Violências domésticas, vivências e dificuldades no Semiárido Nordestino, as características dos crimes tipificados como violência doméstica em dois municípios do sertão do Estado de Sergipe. As/os autoras/as fizeram uma análise minuciosa de documentos oficiais, além de realizar entrevistas com mulheres em situação de violência. Os resultados apontam para os sofrimentos, cuidados, dificuldades e potências invocadas por mulheres e profissionais para lidar com esta problemática na região.

$\mathrm{O}$ artigo intitulado Enfrentamento da violência contra as mulheres no Município de Garanhuns - Pernambuco: entre resistências, afetos e cuidados, de autoria de Patricia Ivanca de Espíndola Gonçalves, Jorge Lyra e Mirella de Lucena Mota traz ao debate as experiências de instituições no combate e enfrentamento à diversas formas de violências que atingem mulheres em uma cidade de porte médio do interior pernambucano.

Em Mãe Maré, o mangue vai acabar? Processos de subjetivação e políticas da mariscagem, Michele de Freitas Farias de Vasconcelos, Yasmin Adriane Mendonça da Rocha e Sandra Raquel de Oliveira Santos focalizam o cotidiano das mulheres do mundo do mangue, enfatizando as estratégias de (re)existências por elas protagonizadas.

Na seção dedicada às pedagogias de gênero destacamos três artigos. No primeiro, "Mulher tem mais facilidade para coisa artística, organização, trabalhos didáticos" - Produção de masculinidades e estratégias pedagógicas nos anos iniciais na roça, os/as autores/as, Antonio Jeferson Barreto Xavier, Fernando Seffner e Maria Carmen Silveira Barbosa apresentam dados etnográficos sobre as práticas pedagógicas de professores homens que atuam nos Anos Iniciais em escolas situadas em região rural do Estado da Bahia. A pesquisa destaca as tensões que se constituem para o desenvolvimento de práticas pedagógicas em contexto que envolve as ruralidades, as masculinidades e a infância. $\mathrm{O}$ segundo artigo denominado As brincadeiras infantis em 
comunidade periférica da cidade de Maceió-AL: as relações de gênero em questão, de Alana Madeiro de Melo Barboza, Paula Orchiucci Miura, Adélia Augusta Souto de Oliveira e Heliane de Almeida Lins Leitão, apresenta dados de investigação sobre estereótipos e relações de gênero constituídas a partir da ludicidade no espaço escolar da educação infantil. Por fim, o terceiro e último artigo elaborado por Linda Brasil Azevedo Santos, Ann Letícia Aragão Guarany e Lívia de Rezende Cardoso, intitulado Gênero, Sexualidade e Currículo: mapeamento das pesquisas acadêmicas no Nordeste brasileiro, traz uma importante investigação no campo da educação sobre produções acadêmicas realizadas nos programas de pós-graduação stricto sensu da região Nordeste do Brasil, presentes na plataforma digital BDTD. As autoras destacam um rico referencial sobre gênero, sexualidade e currículo, incorporando os elementos teórico e metodológicos às análises realizadas dos dados obtidos.

Por fim, é possível afirmar que a produção desse dossiê representa as potencialidades das pesquisas realizadas no e sobre os Nordestes do Brasil, região rica em cultura, política, história, diversidades, solidariedades e muita luta. A interiorização da Educação Superior intensificou essa produção científica e educacional conferindo voz à cientistas, jovens e a comunidade local sobre problemas que antes eram tratados no âmbito de centros e grupos de pesquisa situados nas capitais e cidades de grande porte do País. Portanto, é com muita satisfação que ajudamos a escoar esse conhecimento situado sobre temas variados que envolvem as temáticas de gênero e sexualidades nos Nordestes do País.

Thiago Barcelos Soliva

Patrícia Rosalba Salvador Moura CosTA

\section{Referências}

AQUINO, Estela. Gênero e saúde: perfil e tendências da produção. Revista de Saúde Pública, São Paulo, v. 40, n. especial, p. 121-132, agosto/2006.

ANPOCS, $43^{\circ}$ Encontro Anual da ANPOCS. In: Portal das Ciências Sociais Brasileiras. Disponível em: http://anpocs.com/index.php/43- 
encontro-anual-2019/2750-encontros-anuais/43-encontro/2263caderno-completo-da-programacao, acesso em 18 de janeiro de 2021.

CITELI, Maria Teresa. A pesquisa sobre sexualidade e direitos sexuais no Brasil (1990-2002): revisão crítica. Rio de Janeiro: CEPESC, 2005.

FACCHINI, Regina; DANILIAUSKAS, Marcelo e PILON, Ana Cláudia. Políticas sexuais e produção de conhecimento no Brasil: situando estudos sobre sexualidade e suas conexões. Revista de Ciências Sociais, Fortaleza, v. 44, n.1, p. 161-193, janeiro-junho/2013.

FERNANDES, Estêvão; GONTIJO, Fabiano; TOTA, Martinho e LOPES, Moisés. Diversidade Sexual e de Gênero em Áreas Rurais, Contextos Interioranos e/ou Situações Etnicamente Diferenciadas. Novos descentramentos em outras axialidades - Apresentação. Aceno, Cuiabá, v. 3, n.5, p. 10-13, janeiro-junho/2016.

FERNANDES, Estêvão; GONTIJO, Fabiano; TOTA, Martinho e LOPES, Moisés. Apresentação. Amazônica: revista de antropologia, Belém, v.8, n.1, p. 9-12, 2016.

FRY, Peter. Da Hierarquia à Igualdade: a construção histórica da homossexualidade no Brasil. In: Para inglês ver: identidade e política na cultura brasileira. Rio de Janeiro: Zahar, 1982.

\& MACRAE, Eduard. O que é homossexualidade? Rio de Janeiro: Ed. Brasiliense, 1985.

GASPAR, Maria Dulce. Garotas de Programa: prostituição em Copacabana e identidade social. Rio de Janeiro: Jorge Zahar, 1985.

GUIMARÃES, Carmem Dora. O homossexual visto por entendidos. Rio de Janeiro: Garamond, 2005.

LOYOLA, Maria Andréa. A antropologia da sexualidade no Brasil. Revista Physis, Rio de Janeiro, n. 10, 2000.

NOLETO, Rafael; MAGNI, Claudia Turra e RIETH, Flávia. Cidades do interior, interior das cidades: apresentação. Ponto Urbe, São Paulo, n. 24, p. 1-4, 2019.

OLIVEIRA, Esmael Alves de; NASCIMENTO, Letícia Carolina Pereira do; MORAES, Lorena Lima de e CAETANO, Marcio. Apresentação 
Número Especial Dissidências de Gênero e Sexualidade(s) em Contextos Interioranos e/ou Rurais: Cruzando Temas, Problemas e Perspectivas Contemporâneas. Revista Debates Insubmissos, Caruaru, v. 3, n.9, p. 6-11, 2020.

PERLONGHER, Néstor. $O$ negócio do michê: a prostituição viril em São Paulo. São Paulo: Editora Brasiliense, 1987. 